\title{
PENERAPAN PEMBELAJARAN KOOPERATIF TIPE STAD BERBASIS LESSON STUDY PADA MATA KULIAH ALJABAR LINIER
}

\author{
Ratih Handayani *)
}

\begin{abstract}
The Implementation of STAD based lesson study on algebra subject is the problem in this research. This research is aimed at knowing how the implementation of STAD basedlLesson study on algebra subject is. This is a descriptive qualitative research which was done in three cycles consisting of "plan, do, and see" action in each of the cycles. The research subject was the third semester students of Mathematic departement. Based on the observation result done by the research observers, it was found that the implementation of STAD based Lesson Study enabled the lecturer and the students to learn cooperatively in the teaching and learning process on Algebra subject.
\end{abstract}

Key words: implementation, STAD, lesson study, algebra subject

\section{A. PENDAHULUAN}

Lesson Study merupakan strategi pembelajaran melalui pemberdayaan komunitas untuk dapat saling belajar. Komunitas yang berada di dalam kampus antara lain komunitas dosen dan komunitas mahasiswa. Tidak hanya mahasiswa yang saling belajar, tetapi juga dosen harus saling belajar untuk meningkatkan kualitas sebagai seorang dosen. Dosen tidak hanya meningkatkan pengetahuan, tetapi juga meningkatkan keterampilan membelajarkan mahasiswa sesuai dengan pendekatan pem belajaran dan perkembangan teknologi saat ini.

Pendekatan pembelajaran yang berkembang saat ini, yaitu pembelajaran yang berpusat pada siswa atau mahasiswa. Sekarang dosen tidak harus menstransfer pengetahuan sebanyak mungkin, tetapi cukup menjadi fasilitator dalam perolehan pengetahuan oleh mahasiswa. Smartphone saat ini sudah sangat dekat dengan kehidupan mahasiswa sehingga dosen bisa memanfaatkan smartphone sebagai media untuk menstransfer pengetahuan. Salah satu pengetahuan yang perlu ditransfer kepada mahasisawa, yaitu pengetahuan mengenai aljabar linear.

Aljabar linear merupakan mata kuliah pendalaman bagi SPL dan Matriks sekaligus mata kuliah dasar bagi mata kuliah yang lain, misalnya analisis vektor. Oleh karena itu, mahasiwa harus menguasai matakuliah ini. Namun, pada kenyataannya, hasil belajar mahasiswa tidak sesuai dengan yang diharapkan. Yang mendapatkan nilai baik dan sangat baik hanya $45 \%$. Melihat keadaan ini dosen pengampu bersama dosen-dosen serumpun berusaha untuk memperbaiki keadaan dengan pertama-tama mencari 
penyebab dari permasalahan tersebut. untuk mengetahui bagaimana penerapan Permasalahan tersebut salah satu nya pembelajaran kooperatif tipe STAD berbasis disebabkan oleh mahasiswa tidak "saling” lesson study pada mata kuliah Aljabar Linear. belajar akibat pembelajaran yang didominasi oleh dosen. Dosen menjadi satu-satunya sumber ilmu, akibatnya mahasiswa hanya menerima informasi dan tidak mengkonstruksi sendiri pengetahuannya. Dengan demikian, perlu diupayakan pembelajaran yang dapat mengolaborasikan antara dosen-dosen, dosen-mahasiswa, mahasiswa-mahasiswa, yaitu pembelajaran dengan menggunakan Lesson Study.

Salah satu model pembelajaran yang dapat disertakan untuk membuat mahasisawa saling belajar dalam pelaksanaan lesson study, yaitu pembelajaran kooperataif tipe Student Team Acheivement Divisionss (STAD). STAD merupakan salah satu metode pembelajaran kooperatif yang paling sederhana dan baik untuk permulaan bagi para guru yang baru menggunakan pembelajaran kooperatif. STAD akan banyak melibatkan hubungan sesama mahasiswa dalam proses pembelajaran, sedangkan lesson study akan memungkinkan dosendosen serumpun bekerja sama dalam merancang, melaksanakan, dan meng evaluasi pembelajaran

Berdasarkan uraian tersebut maka dalam penelitian ini yang dikaji, yaitu penerapan pembelajaran kooperatif tipe STAD berbasis lesson study pada mata kuliah Aljabar Linear. Tujuan penelitian ini, yaitu

\section{B. KAJIAN TEORI}

Aljabar linear merupakan salah satu mata kuliah keterampilan pada program studi pendidikan matematika. Bahan kajian pada matakuliah ini antara lain sistem persamaan linear, matriks, vektor, nilai dan vektor eigen, transformasi linear. Beberapa dari bahan kajian tersebut merupakan dasar bagi mata kuliah selanjutnya, misalkan analisis vektor. Oleh karena itu, dibutuhkan pemahaman yang matang pada mata kuliah ini.

Menurut Slavin (2008:11) dalam pembelajaran STAD para siswa dibagi dalam kelompok belajar yang terdiri atas empat orang yang berbeda-beda tingkat kemampuan, jenis kelamin, dan latar belakang sukunya. Hal ini senada dengan Trianto (2009:68) yang menyatakan bahwa "STAD merupakan salah satu dari tipe pembelajaran kooperatif dengan menggunakan kelompok-kelompok kecil dengan jumlah anggota tiap kelompok 4-5 orang siswa secara heterogen”.

Pembelajaran STAD memiliki lima komponen utama. Menurut Slavin (2008:158) lima komponen tersebut, yaitu:
a. Presentasi Kelas
b. Tim
c. Kuis
d. Skor Kemajuan Individual
e. Rekognisi Tim 

Lesson study merupakan suatu kegiatan untuk meningkatkan kualitas pembelajaran yang bentuk kegiatannya berupa kegiatan kolaboratif. Lesson study pertama kali dikembangkan di Jepang pada tahun 1900-an. Menurut Sudrajat dalam Sandi (2010:9) lesson study merupakan salah satu upaya untuk meningkatkan kualitas pembelajaran yang dilaksanakan secara kolaboratif dan berkelanjutan oleh sekelompok guru dan peningkatan kualitas pembelajaran akan berdampak langsung pada peningkatan hasil belajar.

Manfaat penerapan lesson study menurut Rusman (2010:394), yaitu:.

1. meningkatnya pengetahuan guru tentang materi ajar dan pembelajarannya;

2. meningkatnya pengetahuan guru tentang cara mengobservasi aktivitas belajar siswa;

3. menguatnya hubungan kolegalitas baik antarguru maupun dengan observer lain selain guru;

4. menguatnya hubungan antara pelaksanaan pembelajaran sehari-hari dengan tujuan pembelajaran jangka panjang;

5. meningkatnya kualitas rencana pembelajaran.

\section{METODOLOGI PENELITIAN}

Metode yang digunakan dalam penelitian ini, yaitu deskriptif kualitatif. Metode deskriptif kualitatif menurut Sugiono (2010:15) adalah metode penelitian yang berlandaskan pada filsafat positivisme, digunakan untuk meneliti pada kondisi objek yang alamiah, (sebagai lawannya adalah eksperimen). Peneliti merupakan instrumen kunci. Pengambilan sampel sumber data dilakukan secara purposive dan snowbaal. Teknik pengumpulan dengan trianggulasi, analisis data bersifat induktif/ kualitatif, dan hasil penelitian kualitatif lebih menekan makna daripada generalisasi.

Pelaksanaan pembelajaran STAD berbasis lesson study dilaksanakan dalam 3 siklus yang setiap siklus terdiri dari 3 kegiatan, yaitu plan, do, see. Mahasiswa yang menjadi subjek penelitian, yaitu mahasiswa program studi pendidikan matematika semester III dengan jumlah 19 orang. Teknik pengumpulan data diperoleh dari hasil observasi dan catatan lapangan yang dilakukan oleh para observer.

\section{HASIL PENELITIAN}

Pelaksanaan lesson study memiliki 3 fase, yaitu plan (perencanaan), do (pelaksanaan), dan see (refleksi). Pada fase plan, dosen model beserta beberapa dosen serumpun melakukan penyusunan rencana pembelajaran. Beberapa hal yang perlu diperhatikan saat penyusunan rencana pembelajaran ini, yaitu taraf kesulitan materi ajar, metode dan strategi pembelajaran yang harus mampu mengaktifkan mahasiswa, alokasi waktu yang tersedia, dan tugas yang dapat meningkatkan kemampuan mahasiswa, serta karakteritik mahasiswa. Hasil dari 
penyusunan rencana pembelajaran ini disusun dalam bentuk lesson design.

Fase selanjutnya, yaitu do. Fase do merupakan implementasi dari lesson design yang telah disusun sebelumnya. Dalam pelaksanaan ini, ketika dosen mengajar, dosen akan dibantu oleh beberapa observer yang akan mengamati aktivitas mahasisawa maka Sebelum menerapkan lesson design dalam pembelajaran, dosen model terlebih dahulu menyosialisasaikan lesson design yang telah dibuat kepada beberapa observer. Hal ini dilakukan agar observer mengetahui apa yang hendak yang diamati dan apa yang hendak dituju oleh dosen model.

Fase terakhir, yaitu see. Pada fase ini dosen model beserta beberapa observer yang telah melakukan do akan mereflek- sikan hasil pelaksanaannya. Proses refleksi dimulai dengan dosen model yang menyampaikan hasil pelaksanaannya dan lesson learn yang didapatkannya. Kemudian dilanjutkan dengan penyampaian hasil amatan oleh observer. Terakhir, pengambilan kesimpulan mengenai apa saja yang perlu diperbaiki oleh dosen model.

Pelaksanaan pembelajaran dengan menggunakan model pembelajaran kooperatif tipe STAD berbasis pada mata kuliah aljabar linier dilaksanakan pertama kali pada tanggal 26 Agustus 2017. Dengan beberapa orang observer, yaitu Venty Meilasari M.Pd., Fhela Vhantoria Ningrum, M.Pd., Karsoni, M.Pd., dan Darwanto, M.Pd. Siklus 2 dilaksanakan pada tanggal 02 Oktober 2017. Pada siklus 2, peren- canaan disusun berdasarkan evaluasi pada siklus 1. Pelaksanaan siklus 2 melibatkan 2 orang observer, yaitu Venty Meilasari, M.Pd., dan Darwanto, M.Pd. Siklus terakhir dilaksanakan pada tanggal 09 Oktober 2017 dan melibatkan 2 orang observer, yaitu Venty Meilasari, M.Pd.

Contoh lesson design yang telah tersusun adalah sebagai berikut.

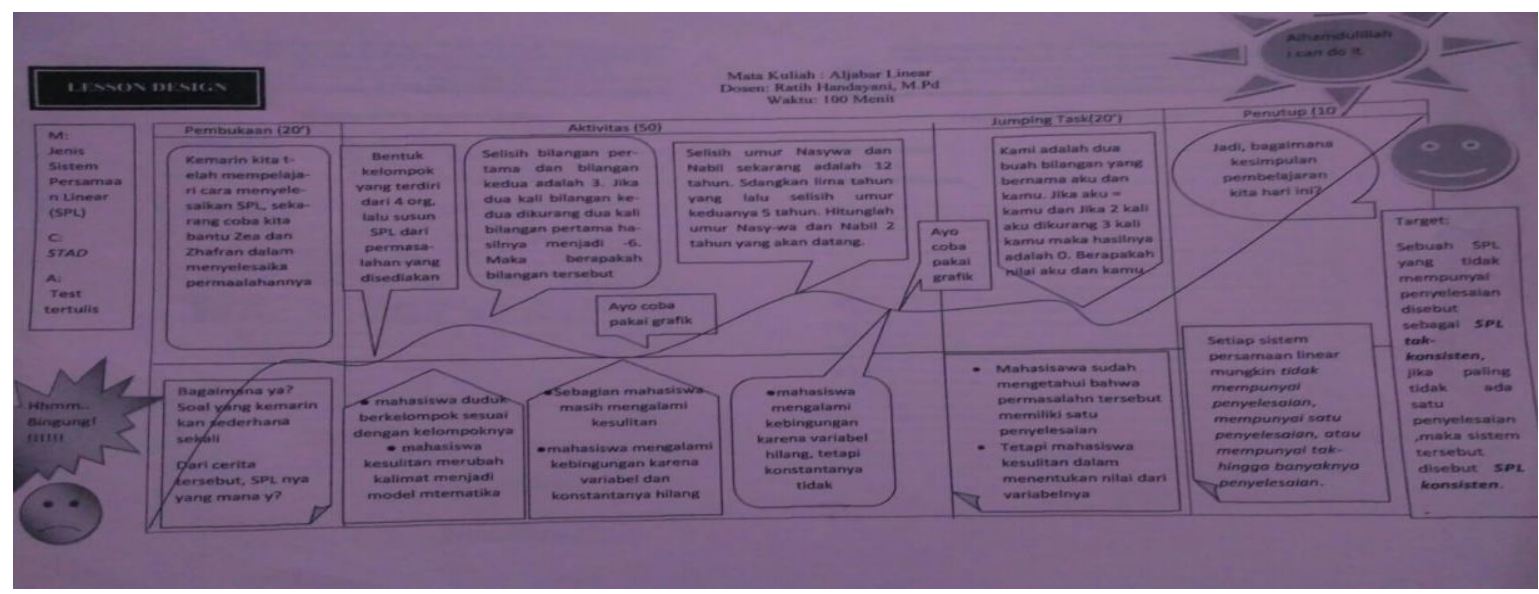

Lesson design tersebut telah dilaksanaan di kelas yang dihadiri oleh 19 mahasiswa yang terdiri dari 5 kelompok. Masing kelompok terdiri dari 4 orang, 
terkecuali kelompok terakhir hanya 3 orang. Pembelajaran dilaksanakan sesuai dengan langkah-langkah pembelajaran yang telah disusun. Kemudian hasil pelaksanaannya akan direfleksikan dalam fase berikutnya.

Adapun contoh hasil amatan dari beberapa observer adalah sebagai berikut.

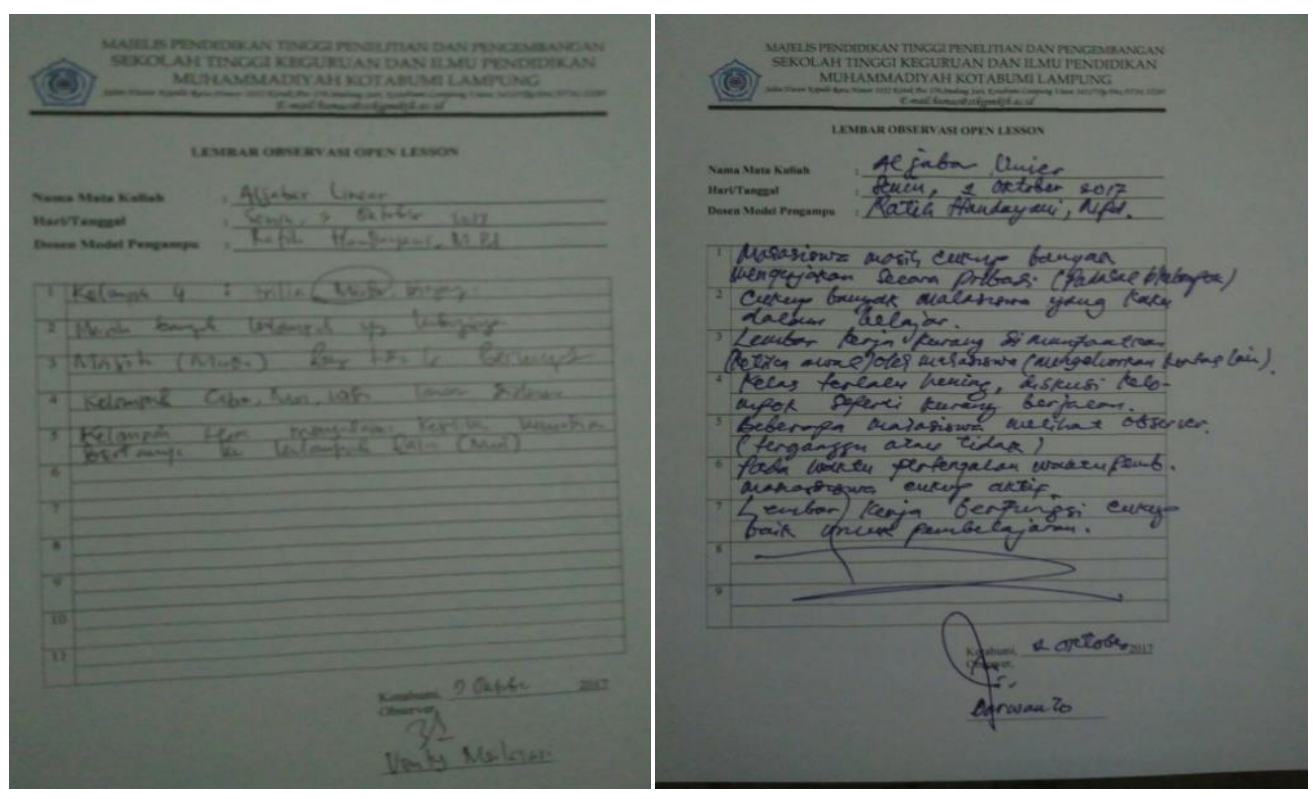

E. PEMBAHASAN HASIL PENELI- lain untuk berdiskusi menyelesaikan Lembar

\section{TIAN}

Penerapan pembelajaran kooperatif tipe STAD berbasis lesson study pada mata kuliah Aljabar linear merupakan hal baru. Pembelajaran yang biasa digunakan pada mata kuliah ini, yaitu pembelajaran langsung yang menjadikan dosen sebagai satu-satunya sumber ilmu. Hal ini menyebabkan mahasiswa menjadi pasif dan tidak terbiasa untuk mengonstruksi sendiri penetahuan yang didapat.

Pada pembelajaran kooperatif tipe STAD berbasis Lesson Study siswa belajar dalam kelompok kecil. Dalam kelompok tersebut siswa akan berkolaborasi satu sama Kerja yang dibagikan. Jika dalam kelompoknya siswa mengalami kesulitan, siswa diperbolehkan untuk bertanya kepada kelompok lain. Apabila semua kelompok mengalami kesulitan, baru dipersilakan bertanya kepada dosen.

Pada siklus 1, hasil observasi menunjukkan beberapa hal yang cukup baik, yaitu pembagian kelompok sudah baik sehingga kelompok ini dapat digunakan seterusnya. Kemudian lembar kerja (LK) dibagikan perindividu, serta isi LK baik dan sesuai dengan materi ajar. Namun, ada beberapa hal yang perlu diperbaiki, antara lain mahasiswa masih mengerjakan LK secara mandiri dalam 
kelompok (belum berdiskusi), peran dosen masih mendominasi sebagai sumber ilmu, ada lesson design yang tidak dilaksanakan, cukup banyak mahasiswa yang kaku dalam pembelajaran ini, seta pemanfaatan LK yang belum maksimal.

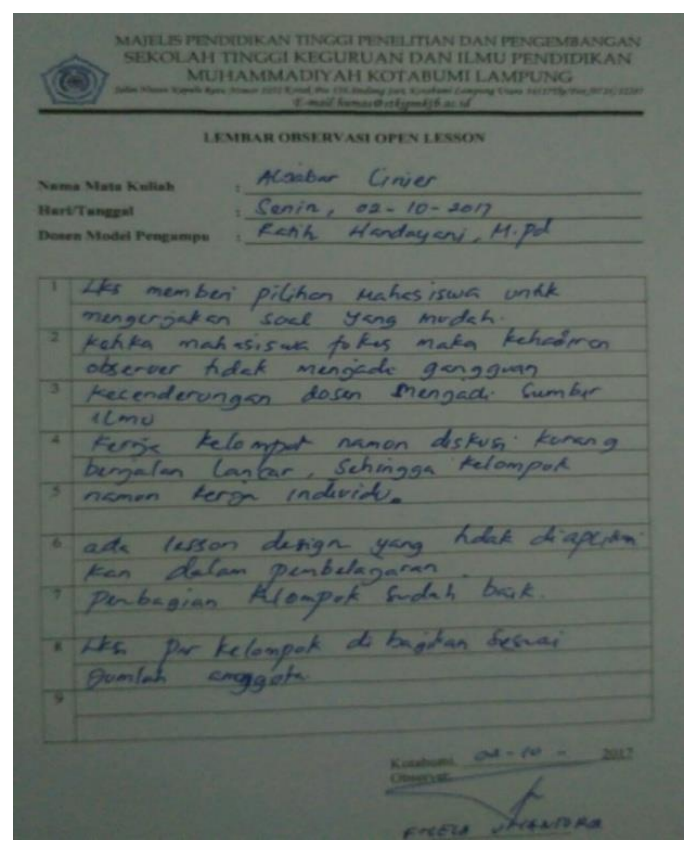

Hasil refleksi tersebut digunakan sebagai perbaikan pada siklus kedua, antara lain dalam menyusun lesson design lebih menyesuaikan dengan alokasi waktu. Dengan demikian, pembelajarannya lebih sesuai dengan rencana dan lesson design dapat dijalankan semua. Dosen model juga mengurangi keterlibatannya ketika mahasiswa berdiskusi.

Pada refleksi siklus kedua, ada beberapa kemajuan yang diperoleh. Ada beberapa kelompok yang sudah aktif berdiskusi dalam kelompoknya. Bahkan adapula yang ketika kelompoknya mengalami kesulitan maka kelompok tersebut bertanya ke kelompok lain. Hal ini baik karena peran dosen sebagai sumber ilmu sudah berkurang. Kemudian ketika proses penyimpulan mahasiswa menyampaikan hasil diskusinya dengan baik dan siswa tampak puas dengan hasil diskusinya. Namun, masih ada beberapa hal yang pelu diperbaiki, yaitu ada beberapa mahasiswa yang masih pasif dalam kegiatan diskusi.

Hasil refleksi pada siklus kedua trus diperbaiki dalam perencaan siklus ketiga, antara lain setiap ketua kelompok harus memastikan semua anggotanya mampu menyelesaikan LK dengan baik. Pelaksanaan siklus ketiga semakin baik, terlihat dari hasil observasi para observer yang menyatakan bahwa diskui berjalan dengan baik, terlihat siswa antusias, mahasiswa lebih rileks.

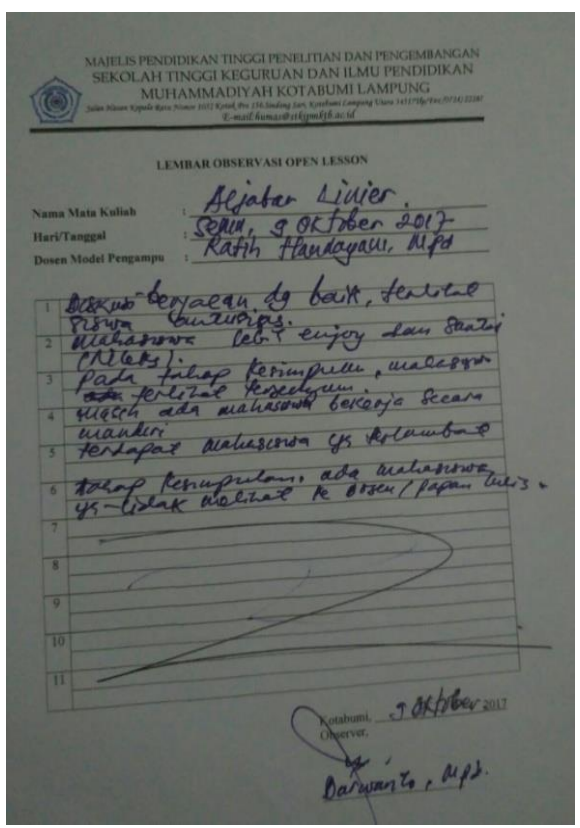

\section{F. SIMPULAN DAN SARAN}

\section{Simpulan}

Berdasarkan hasil amatan para observer maka penerapan pembelajaran kooperatif tipe 
STAD berbasis lesson study dapat membantu dosen dan mahasiswa untuk saling belajar pada mata kuliah aljabar linear. Penerapan pembelajaran kooperatif tipe STAD berbasis lesson study memberikan peningkatan pada cara belajar mahasiwa yang semula bersumber pada dosen menjadi bersumber pada teman sejawat. Kemudian mahasisawa juga aktif mengonstruksi sendiri pengetahuannya sehingga ilmu yang diperoleh akan bertahan. Para observer dan dosen model sepakat bahwa setiap anggota kelompok mampu bekerja sama dengan baik.

\section{Saran}

Berdasarkan hasil penelitian dan pembahasan agar mendapatkan hasil yang lebih optimal disarankan hal-hal berikut ini.

1. Dosen dapat menerapkan pembelajaran kooperatif tipe STAD berbasis lesson study sebagai salah satu alternatif dalam pembelajaran.

2. Pembaca dan peneliti lain yang ingin mengembangkan penelitian lanjutan mengenai pembelajaran kooperatif tipe STAD berbasis lesson study hendaknya melakukan pembiasaan pembelajaran terlebih dahulu dan membuat buku tuntunan guru dan siswa sebagai wadah bagi guru untuk mencatat atau melihat kekurangan maupun perkembangan belajar siswa secara berkelanjutan dan untuk melihat bagaimana keterlaksanaan pembelajaran yang diterapkan oleh guru.

\section{DAFTAR RUJUKAN}

Rusman. 2010. Model-Model Pemebelajaran Mengembangkan Profesionalisme Guru. Bandung: Raja Grafindo Persada.

Sandi. 2010. Pengembangan Bahan Workshop Lesson study Serta Implementasi Oleh Guru Matematika di Madrasah Ibtidaiyah Negeri 1 Pangkalpinang. Tesis tidak diterbitkan. Palembang: Fakultas Keguruan dan Ilmu Pendidikan.

Slavin, R.E. 2008. Cooperative Learning Teori, Riset dan Praktik. Terjemahan: Nurulita Yusron. Bandung: Nusa Media.

Sugiono. 2010. Metode Penelitian Kuantitatif Kualitatif Dan $R \& D$. Bandung: Alfabeta.

Trianto. 2009. Mendesain Model

Pembelajaran Inovatif-Progesif. Jakarta: Kencana. 